\title{
Urbanization of Colombo City and Its Impact on Land Surface Temperature from 2001-2019
}

\author{
Dissanayake Dmdok ${ }^{*}$, Kurugama Kakm \\ Department of Earth Resources Engineering, Faculty of Engineering, University of Moratuwa, Katubedda, Sri Lanka
}

Email address:

kithsiridissanayake@yahoo.com (D. Dmdok)

${ }^{*}$ Corresponding author

\section{To cite this article:}

Dissanayake Dmdok, Kurugama Kakm. Urbanization of Colombo City and Its Impact on Land Surface Temperature from 2001-2019. American Journal of Environmental Protection. Vol. 10, No. 3, 2021, pp. 66-76. doi: 10.11648/j.ajep.20211003.12

Received: June 22, 2021; Accepted: July 5, 2021; Published: July 13, 2021

\begin{abstract}
The Urban Heat Island (UHI) is a metropolis whose temperature is several degrees higher than the surrounding rural areas. In connection with the UHI phenomenon, the earth's surface temperature (LST) was estimated using Landsat satellite imagery covering the city of Colombo. The results showed that the UHI effect spread to the north, east, and southeast of Colombo City between 2001 and 2019. Analyzing the correlation between the LST, normalized vegetation difference index (NDVI) and normalized difference index (NDBI), it is found that there is an inverse correlation between NDVI and LST; however, it is reported that NDBI is associated with the four LST periods of 2001, 2009, 2016 and 2019 which indicates that vegetation can weaken UHI, while built-up land can enhance the UHI. The result of albedo analysis shows that low albedo has a greater impact on the formation of UHI. According to this environmental assessment using the Urban Thermal Difference Index (UTFVI), 27\% of the region suffers the worst thermal stress. Therefore, in future urban planning, mitigation measures should be taken to improve the quality of the life of the people and the environment in the city of Colombo.
\end{abstract}

Keywords: Urban Heat Island (UHI), NDVI, NDBI LST, UTFVI, Albedo

\section{Introduction}

After the industrial revolution, globalization and the migration of countries to cities are driving urbanization. This is the main reason for redesigning land use/land cover to suit a country's population needs and economic activities. Starting from $34 \%$ in 1960 , the world's population is urban, which means that most of the population lives in cities rather than rural areas [1]. In 2015-2020, 2020-2025 and 20252030 , the world urban population expect to grow by $1.84 \%$, $1.63 \%$ and $1.44 \%$ each year [2]. It is a common characteristic of urban areas having single use zoning, roads and bridges, low density residential housing, government administrative buildings, private and public sector trading and commercial buildings, airport and harbours, warehouses, various industries, public and private transportation, leading to rapid land use pattern changes [3]. These urban areas tend to have high, thermal conductivity and throughput in addition to the solar energy absorption, because most structures (such as streets, sidewalks, parking lots, roofs and darker-surfaced buildings) have used construction materials with low reflectivity. Therefore, the reflectance of solar radiation is low [4]. As a result, urban areas temperature tends to be significantly higher than in the surrounding areas. This difference of temperature forms a ground effect called "urban heat island" [5]. The rising area makes a major contribution to the formation of UHI by capturing the solar radiation incident during the day and the solar radiation re-since then emitting at night [6]. Evapotranspiration, photosynthesis, and the reduction of soil surface temperature (LST) can cause shade [7], and the cover of forests and vegetation reduces the ambient temperature by releasing water vapour. Heat radiation from houses, factories, cars and air conditioners are other main sources [8]. Since the late 1990s, due to accelerated expansion, Sri Lanka's land use near Colombo has undergone tremendous changes and urban population has begun to grow facing tremendous environmental pressure and poor land use planning. According to the Population and Housing Census carried out in 2012, the western provinces registered the largest number of households, only in Colombo. It has 558,755 residents, of which Colombo is the most densely popular city in the country. Sri Lanka $(15,101$ 
people $/ \mathrm{km}^{2}$ ). Therefore, it is imperative to consider the impact of rapid urban expansion on the environment, which will cause the disappearance of urban vegetation every year, and at the same time accurately, economically, and quickly record the heat energy released from each earth's surface to the environment is also a difficult task. The integration of remote sensing and geographic information system plays an important role as a powerful and efficient tool for assessing surface temperature in order to study UHI phenomena in any urban area and can be applied to many other fields as well. [9], [10]. Although several studies on the effect of UHI in Colombo have been carried out [11] [12], the spatial ecological assessment of UHI effect using UTFVI is still lacking for Colombo city. Therefore, the main objectives of this study are: a) Determine the temporal and spatial distribution of ultra-high thermal effect behaviour, and evaluate the ecological conditions of Colombo; b) Study the relationship between LST, NDVI and NDBI; c) Determine the land use/ coverage distribution and its impact on ultra- high heat phenomenon; d) Determine the change of urban surface albedo; e) Compile the urban thermal field difference index (UTFVI), and determine the warning area with the greatest thermal discomfort heat disaster.

\section{Methodology}

\subsection{Study Area}

In this research study considering the highest population, building density, ports, trading and commercial activities and as the administrative and commercial hub of Sri Lanka, Colombo city was selected (Figure 1). The population of the study area is about 613,000 . Colombo city is the administrative and economic center of the country and its located between $6^{\circ} 55-6^{\circ} 59 \mathrm{~N}$ and $79^{\circ} 51-79^{\circ} 53 \mathrm{E}$, covering an area of more than 37 square kilometers. Colombo is one of the urbanized cities in Southeast Asia.

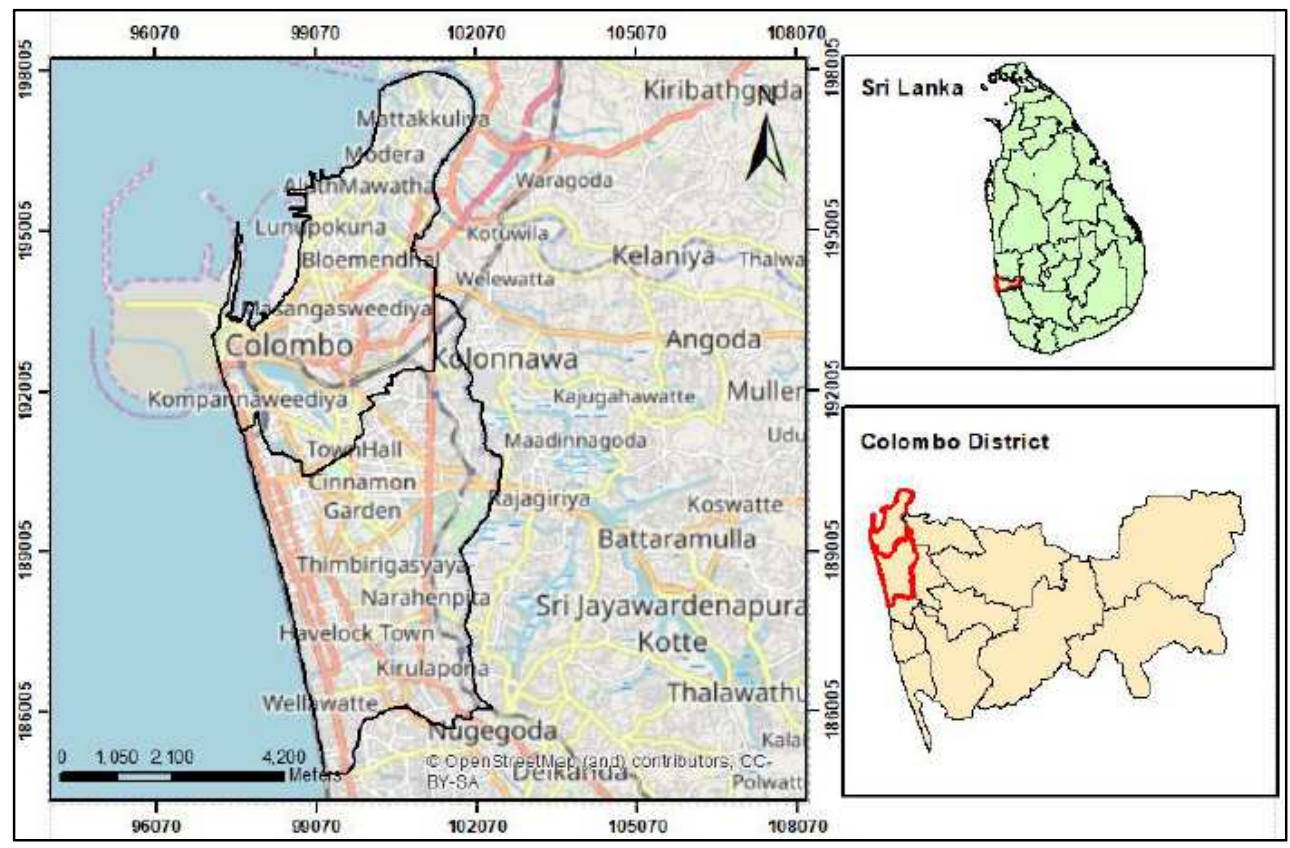

Figure 1. The study area, Colombo City, Sri Lanka.

\subsection{Data Sources}

Table 1. Characteristics of Landsat TM, ETM+ \& OLI/TIRS data.

\begin{tabular}{|c|c|c|c|c|c|c|}
\hline Acquisition Date & Satellite Type & Cloud Cover (\%) & Path & Row & Sun Elevation (Degree) & Time (GMT) \\
\hline $03 / 14 / 2001$ & Landsat 7 ETM+ & 4.00 & 141 & 55 & 57.90309966 & $4: 44: 13$ \\
\hline $02 / 8 / 2009$ & Landsat $5 \mathrm{TM}$ & 12.00 & 141 & 55 & 50.49876176 & $4: 39: 37$ \\
\hline $01 / 27 / 2016$ & Landsat 8 OLI / TRIS & 4.71 & 141 & 55 & 51.46836212 & $4: 53: 59$ \\
\hline $03 / 31 / 2019$ & Landsat 8 OLI / TRIS & 1.98 & 142 & 55 & 62.89190086 & $4: 59: 39$ \\
\hline
\end{tabular}

Almost cloudless 4 Landsat satellite images of 3 different satellite sensors Landsat 8 (OLI/TIRS), Landsat 7 (ETM+) and Landsat $5(\mathrm{TM})$ which has the spatial resolutions of 100 , $60 \mathrm{~m}$, and $120 \mathrm{~m}$ and already georeferenced to UTM coordinate system of thermal bands obtained on $14^{\text {th }}$ March $2001,8^{\text {th }}$ February $2009,27^{\text {th }}$ January 2016 , and $31^{\text {st }}$ March 2019 shown in the Table 1, were used for this study. Other
Auxiliary Data such as Temperature information for 12 months of year 2001, 2009, 2016 and 2019 have been obtained from Meteorology Department and Topographic and Colombo regional maps information have been obtained from Survey Department of Sri Lanka and other relevant ancillary data have been obtained from University of Moratuwa. 


\subsection{Land Cover / Use Classification}

Evaluation of the land cover/use changes during 2001 to 2019 was the first step of this study and then supervised classification was used to classify the RGB colour composite of the images acquired in 2001, 2009, 2016 and 2019 in this study. The maximum likelihood algorithm methodology was used in this image classification method considering covariance and variance of spectral response pattern of the pixels and images were classified into 4 land use classes such as water body, vegetation, build up area and barren lands.

\subsection{Land Surface Temperature (LST) Retrieval}

LST retrieval plays a significant role in this study. In this study, the 10 band (thermal band) of the Landsat 8 satellite image was analysed to identify the LST distribution pattern of the city of Colombo by following the method of LST recovery from the thermal band of an image [13]. The thermal band Digital Number (DN) conversation into spectral radiance values will be carried out as per the relation given in the equation (1)

$$
\mathrm{L}_{\lambda}=(\text { Gain } \times \mathrm{QDN})+\text { Bias }
$$

where $\mathrm{L}_{\lambda}$, is the spectral radiance value of the sensor and QDN is quantized calibrated DN value and $\mathrm{L}_{\lambda}$ can be also be expressed as

$$
\mathrm{L}_{\lambda}=\left(\frac{\operatorname{LMAX} \lambda-\mathrm{LMIN} \lambda}{\mathrm{QCALMAX}-\mathrm{QCALMIN}}\right) \cdot(\mathrm{QCAL}-\mathrm{QCALMIN})+\mathrm{LMIN}
$$

Where $\operatorname{LMAX}_{\lambda}$ and $\mathrm{LMIN}_{\lambda}$ are the maximum and minimum spectral radiance values respectively. Whereas, QCALMAX and QCALMIN are the maximum and is the minimum quantified calibrated pixel values respectively. All of these values are available in the image meta data file and spectral radiance value was used to calculate the black body temperatures of the object on the earth according to the equation (3) given below

$$
\mathrm{T}_{\mathrm{B}}=\frac{\mathrm{K} 2}{\ln \left(\frac{\mathrm{K} 1}{\mathrm{~L} \lambda}+1\right)}
$$

Here, K1 and K2 represent the pre-launch calibration constants. To estimate the real LST values corrections are to be made using ground surface emissivity values [14]. Land surface emissivity $(\varepsilon)$ values were calculated using the following equation (4)

$$
\varepsilon=0.004 \mathrm{PV}+0.986
$$

Equation (5) given below was used calculate the Proportion of vegetation.

$$
\mathrm{PV}=\left(\frac{(\text { NDVI-NDVImin })}{(\text { NDVImax }- \text { NDVImin })}\right)^{2}
$$

Where NDVI represents the Normalized Difference Vegetation Index which is derived in the equation (7) and $\mathrm{NDVI}_{\min }$, and $\mathrm{NDVI}_{\max }$ represent the minimum and maximum values of NDVI. The emissivity corrected LST values are calculated using the equation (6).

$$
\begin{gathered}
\mathrm{T}_{\mathrm{S}}=\frac{\mathrm{TB}}{1+\left(\lambda \times \frac{\mathrm{TB}}{\rho}\right) \ln (\varepsilon)} \\
\rho=\mathrm{h} \times(\mathrm{c} / \sigma)=1.438 \times 10-2 \mathrm{mK}
\end{gathered}
$$

Where Ts represents emissivity corrected LST and TB represents the black body temperature in $\mathrm{K}^{0}, \lambda=11.5 \mu \mathrm{m}$, which is the emitted radiance wave length, $\mathrm{h}=6.626 \times 10^{-34}$ Js, which is the Planck's constant, c $=2.998 \times 108 \mathrm{~ms}-1$ is the velocity of light $\sigma=1.38 \times 10-23 \mathrm{JK}-1$ which is the Boltzmann constant and $\varepsilon$ represent the surface emissivity.

\subsection{The Normalized Difference Vegetation Index (NDVI)}

NDVI is one of the most widely used satellite based vegetation indexes. Each feature available on the earth exhibit different absorption and reflection capacity and capability for visible and near infrared region. This phenomenon is used to distinguish attributes available in the earth surface like vegetation, water bodies, and bare land etc. [15]. Therefore, NDVI value of any feature will be calculated using the Red $(0.64-67 \mu \mathrm{m})$ and NIR $(0.85-0.88 \mu \mathrm{m})$ bands of satellite images. NDVI values will be calculated using the formula (7) given below.

$$
\mathrm{NDVI}=\frac{\mathrm{NIR}-\mathrm{R}}{\mathrm{NIR}+\mathrm{R}}
$$

\subsection{The Normalized Difference Built-up Index (NDBI)}

NDBI is a useful parameter which will beneficial to measure the intensity of imperviousness. It highlights the distribution of the heat in the urban areas and use short-wave infrared band and near-infrared band to calculate the NDBI [16]. Therefore, NDBI is given through equation (8).

$$
\mathrm{NDBI}=\frac{\mathrm{SWIR}-\mathrm{NIR}}{\mathrm{SWIR}+\mathrm{NIR}}
$$

Where, SWIR and NIR indicate the short-wave infrared and near-infrared bands within the range of $(1.57-1.65 \mu \mathrm{m})$ and $(0.85-0.88 \mu \mathrm{m})$ respectively.

\subsection{Albedo Calculation Using Landsat Satellite Imagery of Colombo City}

Albedo is an important characteristic of the thermal stability of the earth's surface. The easy definition of albedo is the average proportion of solar energy reflected from the earth's surface [17]. Precise albedo measurements are very much useful to understand the impact of local land changes in the study area. The input data used to calculate the albedo on this study was OLI 2019 Landsat 8 image band DN values, which was converted into the reflectance of the top of atmosphere (TOA) using reflection scaling coefficient factor in the metadata file of Landsat 8 OLI. The equation (9) which is given below is used to convert the DN value of OLI bands to TOA reflectivity.

$$
\rho \lambda^{\prime}=\mathrm{M} \rho^{*} \mathrm{QCAL}+\mathrm{A} \rho
$$


where $\rho \lambda^{\prime}$ represents the TOA, planetary reflectance without solar angle correction; $\mathrm{M} \rho$ and $\mathrm{A} \rho$ represent respectively the multiplicative and additive scale factor specific to the band from the metadata and QCAL represents the quantified and calibrated standard product pixel values. Then corrected the reflectance value with sun angle according to Equation (10).

$$
\rho_{\lambda}=\frac{\rho \lambda^{\prime}}{\operatorname{Cos} \mathrm{SE}}=\frac{\rho \lambda^{\prime}}{\operatorname{Sin} \mathrm{SZ}}
$$

Where $\rho \lambda$ represents the TOA, planetary reflectance; $\Theta_{\mathrm{SE}}$ represents the local solar elevation angle; $\Theta_{\mathrm{SZ}}$ represents the local zenith angle and $\Theta_{\mathrm{SZ}}=90^{\circ}-\Theta_{\mathrm{SE}}$

Calculating the albedo from various satellite sensors, different algorithms have been developed by many researches and to calculate shortwave albedo $\left(\alpha_{\text {short }}\right)$ from Landsat thermal images Researcher, Smith has developed an algorithm in 2010 [18] as described in Equation (11) below.

$$
\alpha_{\text {short }}=\frac{0.356 \rho 1+0.130 \rho 3+0.373 \rho 4+0.085 \rho 5+0.072 \rho 7-0.0018}{0.356+0.130+0.373+0.085+0.072}
$$

Where, $\rho$ represents reflectance of Landsat bands 1, 3, 4, 5 and 7 except band 2 (green). Albedo values classified into five categories in this study, based on the histogram values.

\subsection{Ecological Evaluation of Colombo}

UTFVI) which was described below in the equation 12 was used in this study to identify environmentally critical areas [19] and then quantitatively describe the UHI effect.

$$
\mathrm{UTFVI}=\frac{\mathrm{Ts}-\mathrm{Tm}}{\mathrm{Tm}}
$$

Where Tm is the average LST across the study area

Table 2. Classification of Albedo values in Colombo.

\begin{tabular}{ll}
\hline Albedo Measurements & Land Use change \\
\hline $0.05-0.10$ & Very Less \\
$0.10-0.15$ & Less \\
$0.15-0.18$ & Fairly moderate \\
$0.21-0.27$ & Moderate \\
$>0.27$ & High \\
\hline
\end{tabular}

\section{Results and Discussion}

\subsection{Accuracy Assessment}

Since simultaneous Land Surface Temperature data were not available when the satellite passes the area, daily average air temperature measurements recorded by Department of Meteorology were used to verify the final retrieved LST results obtained from this study (Table 3).

Table 3. Accuracy comparison of retrieved LST.

\begin{tabular}{llll}
\hline Date & Retrieved Mean Temp $\left({ }^{\circ} \mathbf{C}\right)$ & Mean Air Temp $\left({ }^{\circ} \mathbf{C}\right)$ \\
\hline $03 / 14 / 2001$ & 32.67 & 32.00 & Error \\
$02 / 08 / 2009$ & 30.85 & 32.10 & -0.67 \\
$01 / 27 / 2016$ & 32.45 & 34.70 & -1.25 \\
$03 / 31 / 2019$ & 35.26 & 33.20 & +2.25 \\
\hline
\end{tabular}

Thus, the Radiative transfer equation method has given significant accuracy $\left( \pm 2.25^{\circ} \mathrm{C}\right)$, provided good quality retrieved LST data for the analysis of UHIs in the study area.

\subsection{LULC Distribution During 2001 -2019}

The Land Use/ Cover maps of Colombo City area are shown in the Figures 2 and 3 for the year 2001, 2009, 2016 and 2019.

According to results obtained from the classification for the period of 2001 to 2019 , it is noted that decreased the barren land area from $46.42 \%$ to $5.21 \%$ and same area was occupied by the built-up area which is rapidly increased from $45.10 \%$ to $87.08 \%$ from total area. Loss of vegetation cover significantly can be observed in 2009 and 2016 compared to 2001.

\subsection{LST Distribution (2001-2019)}

Figure 4 shows the LST maps of Colombo city in 2001, 2009, 2016 \& 2019 and the statistical description of the retrieved LST values are summarized in the Table 4. Highest and lowest temperature classes are indicated in red and green colors in the figure respectively.

Table 4. Statistical data of LST distribution.

\begin{tabular}{lllll}
\hline year & Max $\left({ }^{\circ} \mathbf{C}\right)$ & Min $\left({ }^{\circ} \mathbf{C}\right)$ & Mean $\left({ }^{\circ} \mathbf{C}\right)$ & Standard Deviation \\
\hline 2001 & 37.9 & 25.86 & 32.8 & 1.64 \\
2009 & 34.67 & 24.6 & 30.85 & 1.34 \\
2016 & 36.32 & 26.2 & 32.45 & 1.22 \\
2019 & 40.33 & 28.71 & 35.26 & 1.64 \\
\hline
\end{tabular}

Areas with highest LST were concentrated in 2001 and 2009 in the vicinity of Colombo harbor and the Pettah area. But in 2016 and 2019 the areas with the highest LST greatly expanded towards northern, eastern, central and south east regions of the city including the port city project area. An overall UHI distribution map was generated by integrating the regions with highest temperature values in each year, (Figure 5.) 

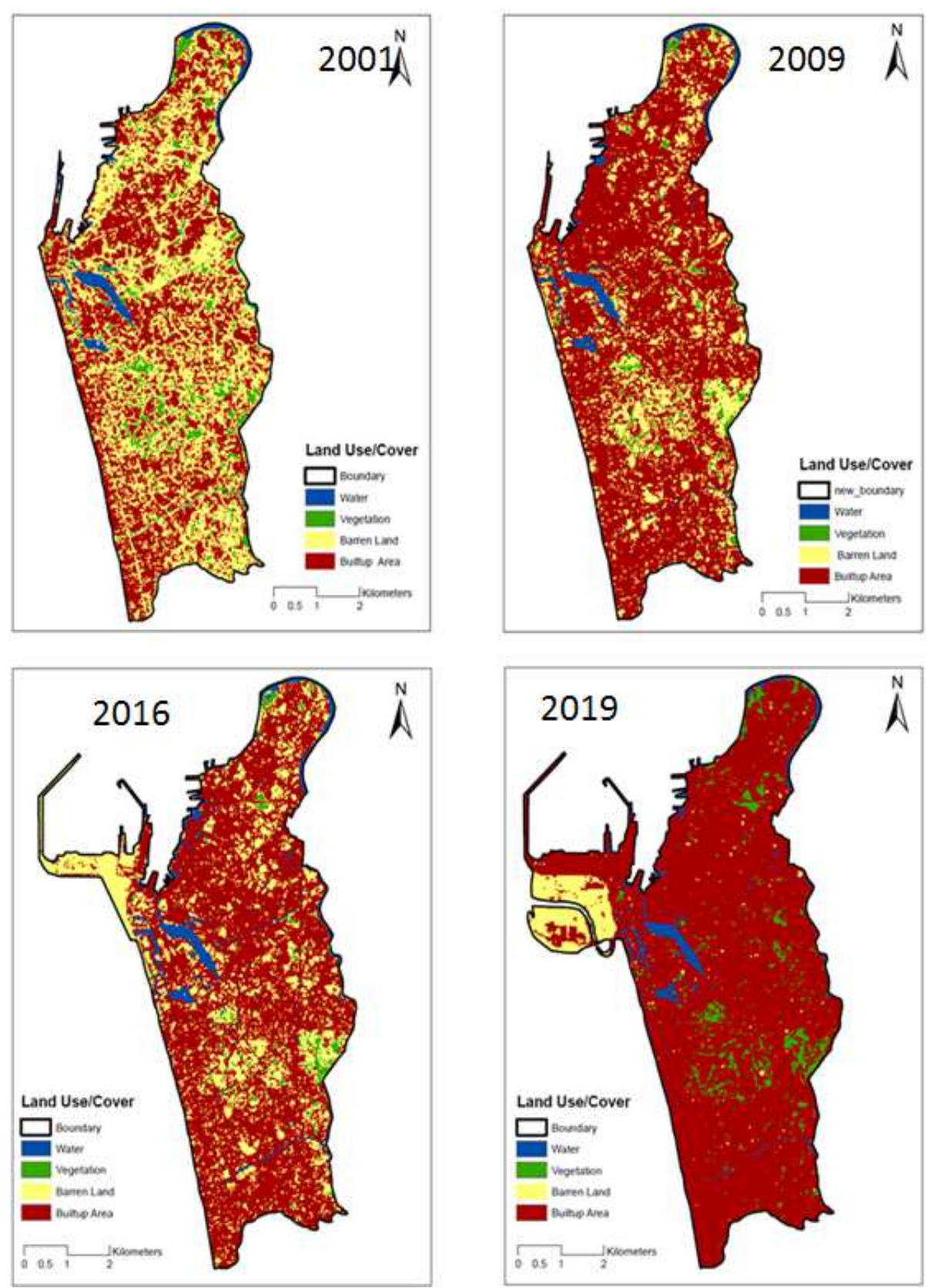

Figure 2. LULC Classification (2001-2019).

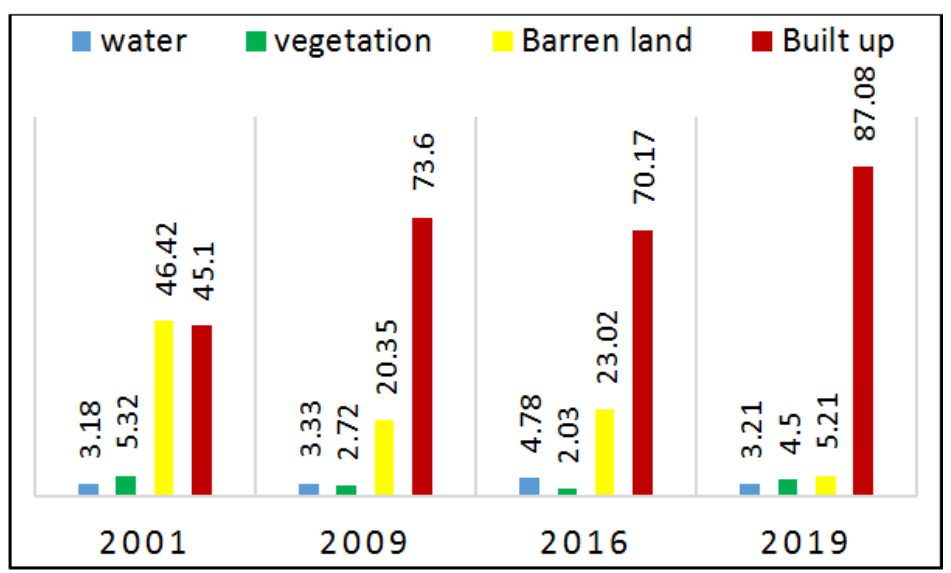

Figure 3. Statistics of LULC distribution. 

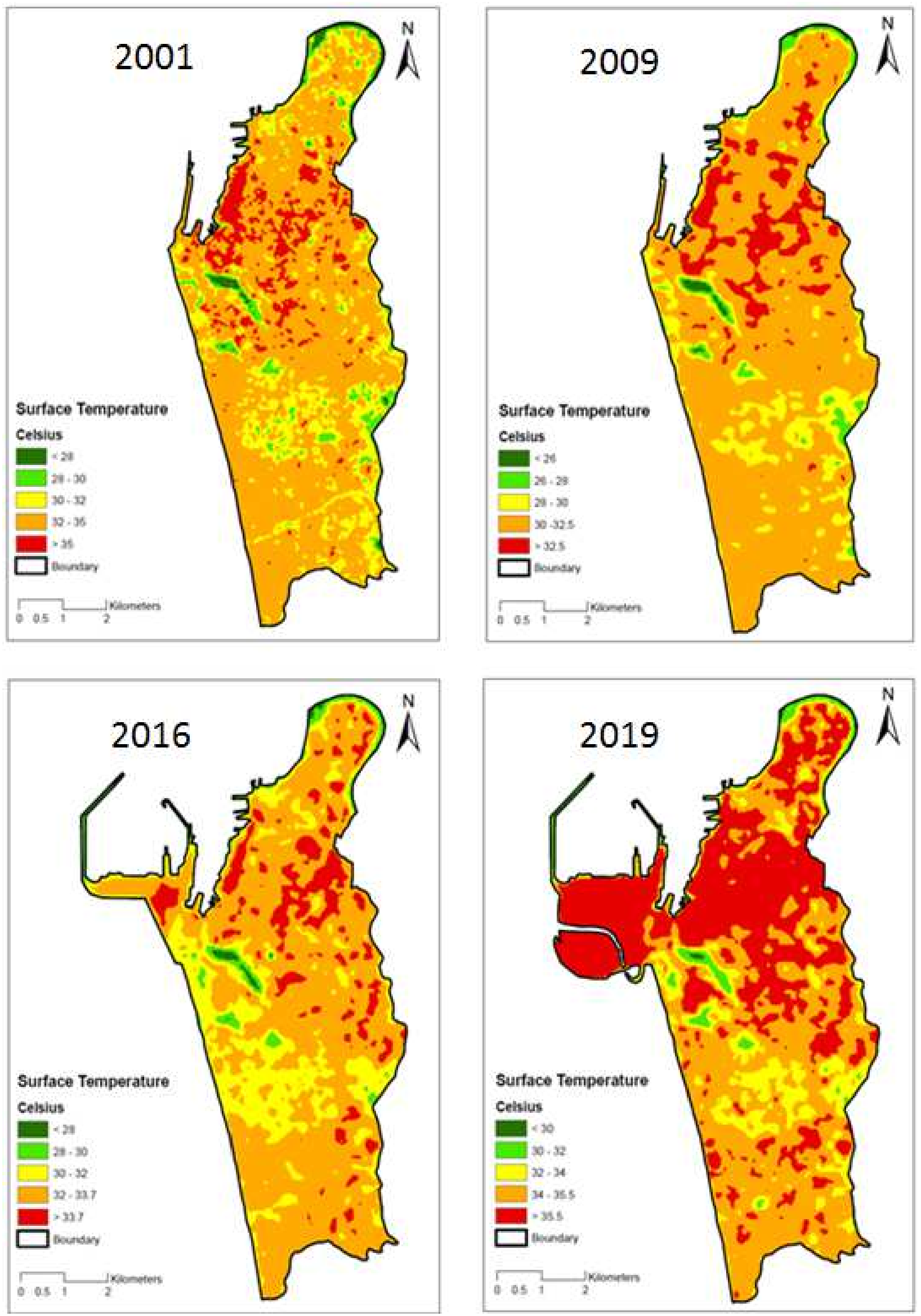

Figure 4. LST Distribution (2001-2019). 


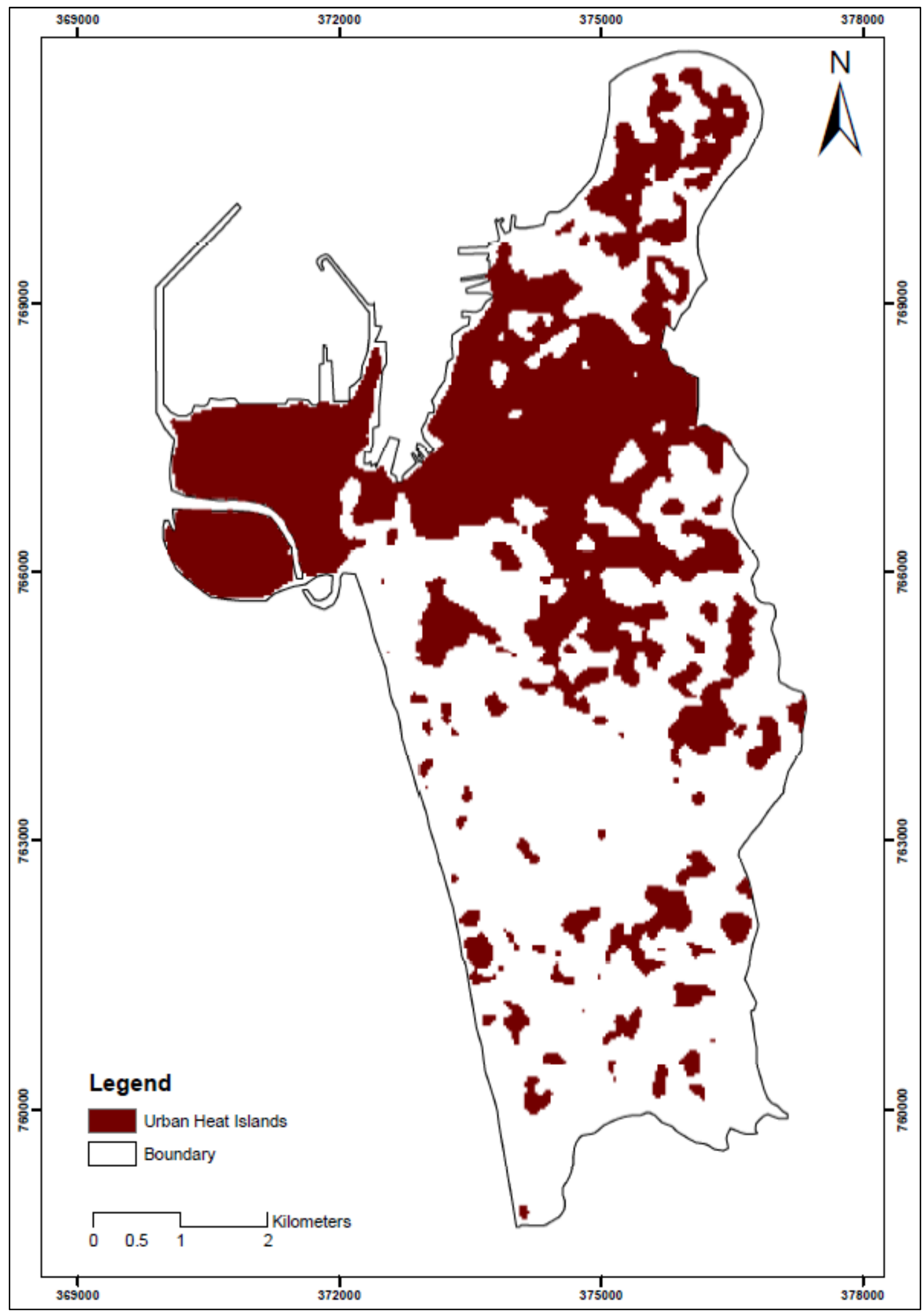

Figure 5. Overall UHI distribution. 


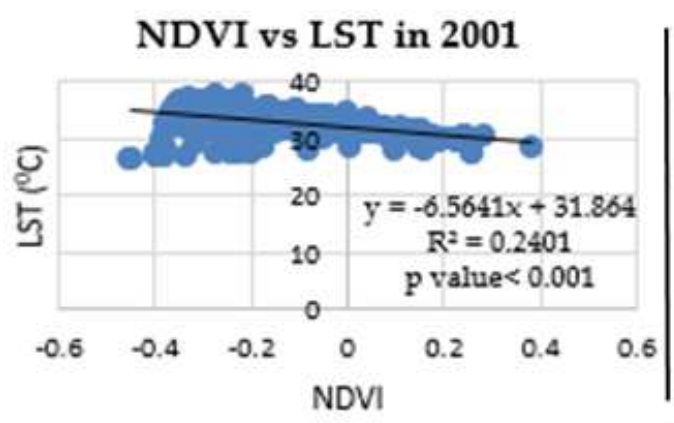

NDVI vs LST in 2016

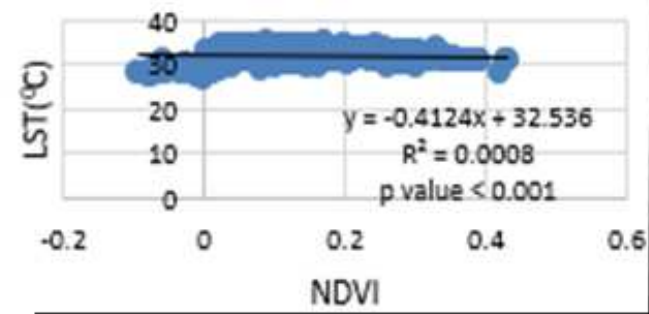

NDBI vs LST in 2001
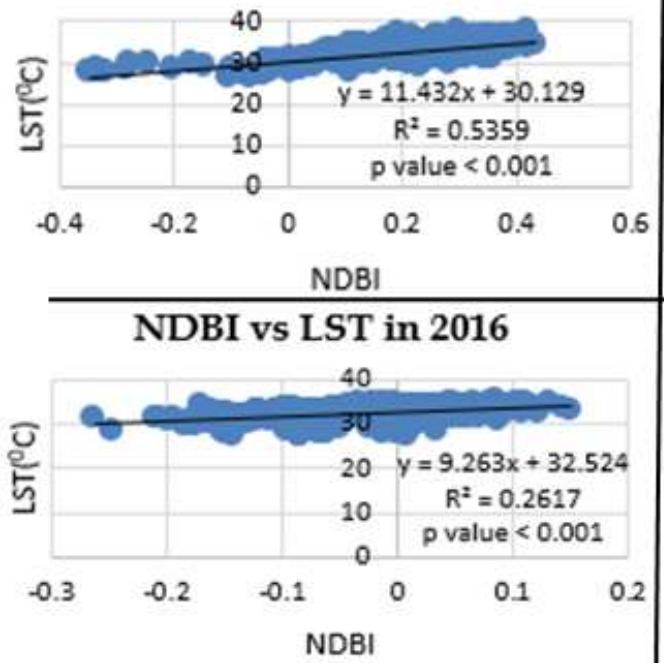

Figure 6. Scatter plots between LST, NDVI \& NDBI.
NDVI vs LST in 2009

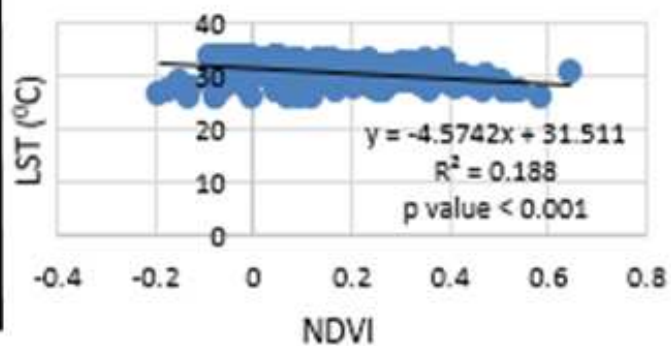

\section{NDVI vs LST in 2019}

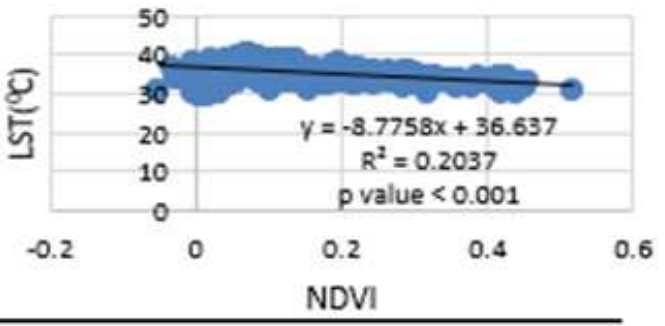

NDBI vs LST in 2009

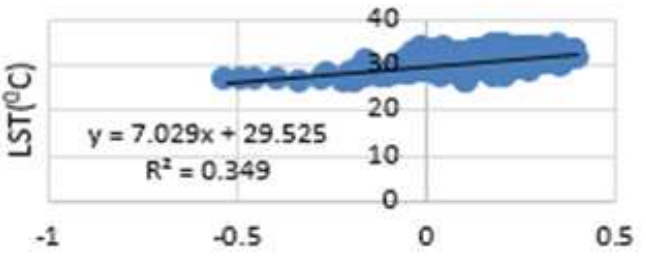

NDBI

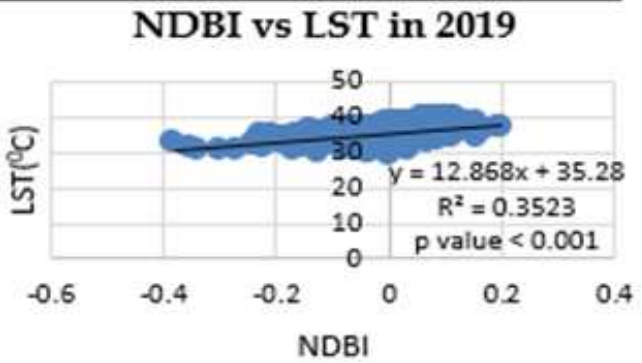

\subsection{Correlation Analysis Between LST, NDVI and NDBI}

Scatter plots, NDVI vs LST and NDBI vs LST in this study shown in the Figure 6 and regression analysis conducted LST vs NDVI and also LST vs NDBI with correlation coefficients are also given in the Table 5 .

The time period taken into consideration for this study showed that inverse relation among NDVI and LST. Although the $\mathrm{R}^{2}$ values had been not that much high, they had been statistically considerable in all four years, for the reason that $\mathrm{p}-$ value $<0.001$.

The period considered for this study confirmed that inverse relation between NDVI and LST Although the $\mathrm{R}^{2}$ values were not that much of high, they were statistically significant in all 4 years, since the $p-$ value $<0.001$.

Generally, the negative coefficient between land on UHI is negative and that the impact of UHI can be weakened by the growth of green lands. it is able to be found that the spatial distribution of NDBI value appreciably follows the spatial styles of LST values. The positive relationships among NDBI and LST have been additionally statistically widespread at every year because the $\mathrm{p}$-value $<0.001$ and $\mathrm{R}^{2}$ values have been relatively higher than NDVI values and the relation between NDBI and LST become more potent than the connection among NDVI and LST. The positive relation between NDBI and LST endorse that constructed up location can strengthen UHI impact.

Table 5. Correlation Analysis results.

\begin{tabular}{lllll}
\hline Correlation & LST & & & \\
\hline NDVI & -0.489 & -0.433 & -0.028 & -0.451 \\
NDBI & 0.732 & 0.5907 & 0.5115 & 0.5935 \\
YEAR & 2001 & 2009 & 2016 & 2019 \\
\hline
\end{tabular}




\subsection{Albedo Distribution in Colombo City}

According to 2019 data the Albedo distribution in Colombo city is shown in the Figure 7 below. Comparing the overall UHI distribution map, Figure 5 and Albedo distribution map, Figure 7, it was confirmed that most of the UHIs were formed due to increase the construction of structure and low and fair albedo surface types such as tar, asphalt concrete roads, cement block pavements, concreate and steel building and structures corrugated roof were present.

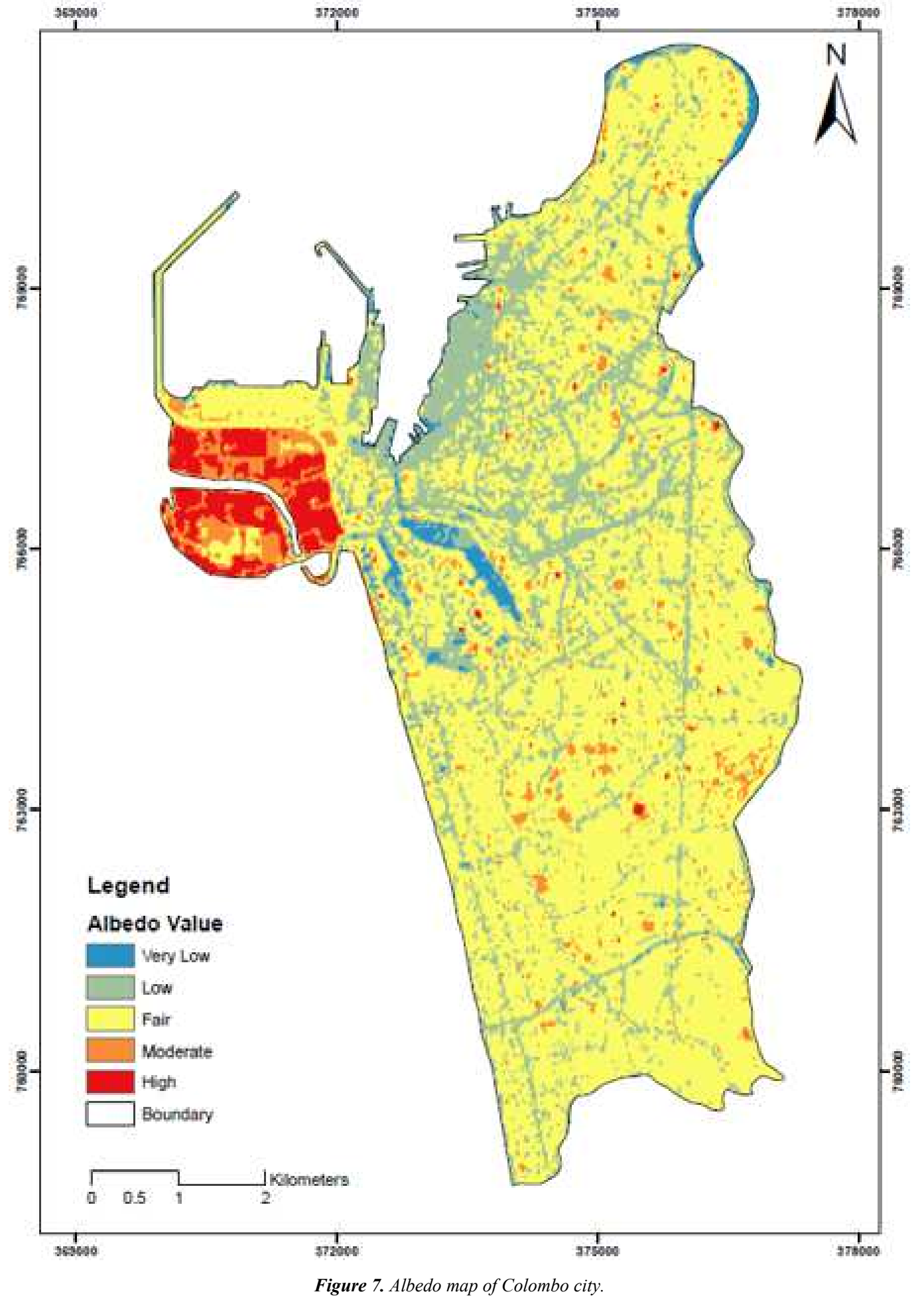

Most of the city buildings roofs finished with concrete slabs or asbestos roofing which are having low albedo values and most of the parking lots available in Colombo city and Jetties of the harbor are constructed with asphalt which are the darker albedo materials are the major contributor for the formation of UHI. 


\subsection{Ecological Evaluation of Colombo City}

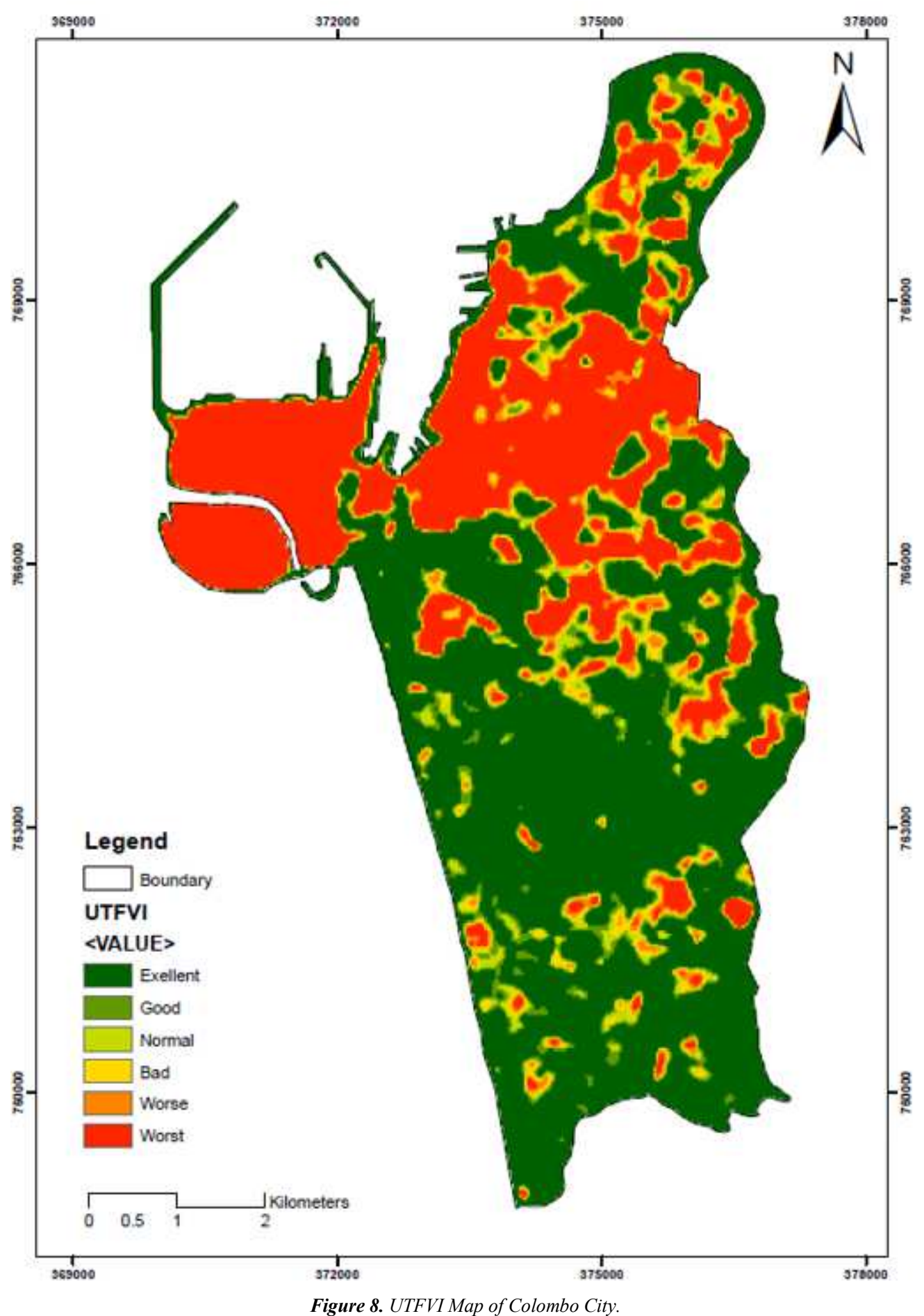

Urban Thermal Difference Index (UTFVI) map is shown in the figure 8 widely used to describe the UHI effect with more precisely. The UTFVI concentration is higher in the area where warmer than the surroundings substantially.

Usually, UTFVI is also used to measure the quality of the urban ecology in terms of the degree of thermal comfort with respect to the UHI effect. Accordingly, this study confirmed that $53.58 \%$ of the areas has healthy microclimate and $27.50 \%$ of the area has worst heat stress.

\section{Conclusion}

This study discovered that LULC pattern notably changed all through 2001 - 2019 because of fast urbanization of the town. 2019 it's been extended into Western, Eastern, Northern, Central and a few a part of the Southern regions. Correlation evaluation discovered that flora cowl can lessen the impact of UHI whilst the built-up 
location can toughen UHI impact. Low albedo substances can boost up UHI phenomenon because of excessive absorption of heat. According to UTFVI, Colombo city limit experiences $53.85 \%$ intense situations of optimal thermal consolation. whilst $27.50 \%$ of the area experiences worst situation. This results indicate that it is a prime and timely important requirement of the country to establish a well-designed urban planning system and proper mitigation strategies to address the UHI in the Colombo city. Therefore, it is proposed to construct cool roof buildings, pervious pavements and extra tree plantations close to city to minimize the EHI.

\section{Acknowledgements}

The authors would like to acknowledge the Department of Earth Resources Engineering, University of Moratuwa providing required funding and laboratory facilities to make this research success and every other person who helped in different ways during this research work.

\section{References}

[1] United nations, (2011). Population, Distribution, Urbanization, Internal Migration and Development: An international perspective. Department of Economic and Social Affairs, Population Division, United Nations.

[2] Who. int. 2021. World Health Statistics. [online] Available at: $<$ https://www.who.int/data/gho/data/themes/topics/topicdetails /GHO/world-health-statistics $>$ [Accessed 13 May 2021].

[3] Akbari, H. and Konopacki, S., 2005. Calculating energysaving potentials of heat-island reduction strategies. Energy Policy, 33 (6), pp. 721-756.

[4] Boice, D., Garza, M. and Holmes, S., 2018. The Urban Heat Island of San Antonio, Texas, from 1991 to 2010. Journal of Geography, Environment and Earth Science International, 17 (2), pp. 1-13.

[5] Jiang, G., Li, Z. and Nerry, F., 2006. Land surface emissivity retrieval from combined mid-infrared and thermal infrared data of MSG-SEVIRI. Remote Sensing of Environment, 105 (4), pp. 326-340.

[6] Oke, T., 1982. The energetic basis of the urban heat island. Quarterly Journal of the Royal Meteorological Society, 108 (455), pp. 1-24.

[7] Weather, 1979. BOUNDARY LAYER CLIMATES. By T. R. Oke. Methuen \& Co. Ltd. 34 (9), pp. 370-370.
[8] Warren, C., 2012. Heat Islands; Understanding and Mitigating Heat in Urban Areas 20122 Lisa Gartland. Heat Islands; Understanding and Mitigating Heat in Urban Areas. London: Earthscan 2011. 192 pp., ISBN: 978-1-84971-298-9 \$64.95. Property Management, 30 (1), pp. 105-106.

[9] Streutker, D., 2002. A remote sensing study of the urban heat island of Houston, Texas. International Journal of Remote Sensing, 23 (13), pp. 2595-2608.

[10] Weng, Q., 2012. Remote sensing of impervious surfaces in the urban areas: Requirements, methods, and trends. Remote Sensing of Environment, 117, pp. 34-49.

[11] Senanayake, I., Welivitiya, W. and Nadeeka, P., 2013. Remote sensing based analysis of urban heat islands with vegetation cover in Colombo city, Sri Lanka using Landsat-7 ETM+ data. Urban Climate, 5, pp. 19-35.

[12] Ranagalage, M., Estoque, R. and Murayama, Y., 2017. An Urban Heat Island Study of the Colombo Metropolitan Area, Sri Lanka, Based on Landsat Data (1997-2017). ISPRS International Journal of Geo-Information, 6 (7), p. 189.

[13] Usgs. gov. 2021. Landsat 7 Data Users Handbook. [online] Available at: <https://www.usgs.gov/core-sciencesystems/nli/landsat/landsat-7-data-users-handbook> [Accessed 13 May 2021].

[14] Pmd. gov. pk. 2021. [online] Available at: $<$ http://www.pmd.gov.pk/rnd/rndweb/rnd_new/journal/vol1 1_issue22_files/4.pdf $>$ [Accessed 13 May 2021].

[15] Chen, X., Zhao, H., Li, P. and Yin, Z., 2006. Remote sensing image-based analysis of the relationship between urban heat island and land use/cover changes. Remote Sensing of Environment, 104 (2), pp. 133-146.

[16] Shuai, Y., Masek, J., Gao, F. and Schaaf, C., 2011. An algorithm for the retrieval of 30-m snow-free albedo from Landsat surface reflectance and MODIS BRDF. Remote Sensing of Environment, 115 (9), pp. 2204-2216.

[17] Salomon, J., Schaaf, C., Strahler, A., Feng Gao and Yufang Jin, 2006. Validation of the MODIS bidirectional reflectance distribution function and albedo retrievals using combined observations from the aqua and terra platforms. IEEE Transactions on Geoscience and Remote Sensing, 44 (6), pp. 1555-1565.

[18] Zaeemdar, S. and Baycan, T., 2017. Analysis of the Relationship between Urban Heat Island and Land Cover in Istanbul through Landsat 8 OLI. Journal of Earth Science \& Climatic Change, 8 (11). doi: 10.4172/2157-7617.1000423.

[19] Chen, L., Zhang, J. and Xu, X., 1999. The correlation of multi-channel thermal infrared remote sensing information and its effect on retrieval of land surface temperature. Chinese Science Bulletin, 44 (17), pp. 1627-1632. 